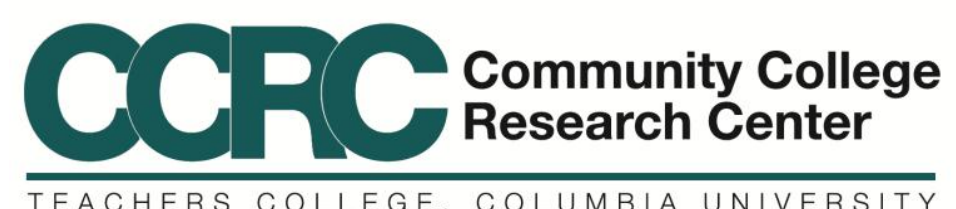

\title{
Valuable Learning or "Spinning Their Wheels"? \\ Understanding Excess Credits Earned by Community College Associate Degree Completers
}

\author{
Matthew Zeidenberg
}

April 2012

CCRC Working Paper No. 44

Address correspondence to:

Matthew Zeidenberg

Senior Research Associate, Community College Research Center

Teachers College, Columbia University

525 West $120^{\text {th }}$ Street, Box 174

New York, NY 10027

212-678-3091

Email: zeidenberg@tc.edu

This research was funded by the Bill \& Melinda Gates Foundation. The author would like to thank Thomas Bailey, Clive Belfield, Sung-Woo Cho, Peter Crosta, Shanna Jaggars, and Davis Jenkins for very helpful comments on earlier drafts of this paper, which have substantially improved it. Thanks also are due to Hana Lahr and Chloe Bellows for research assistance, to Betsy Yoon and Doug Slater for their excellent editorial work, and to the state community college system that provided the data for the research. 


\begin{abstract}
Substantial numbers of students who earn an associate degree from a community college accumulate more college credits than are required. This is an important phenomenon for at least two related reasons. First, it raises the issue of efficiency: Are students getting their degrees in the most expeditious manner, both in terms of time out of the labor market and in terms of the monetary cost of attaining the degree? Second, to what extent is the extra work undertaken by students beneficial to them, even when it does not contribute to degree attainment?

This paper documents the phenomenon of excess credits by examining the credit distributions of six recent cohorts of students in one state's community college system. The analysis is limited to the records of those students who completed associate degrees. The main contribution of this paper to the existing literature is that it considers excess credits in the context of particular degree programs. I first examine the extent of excess credits overall in the community college system. Then I present case studies of individual degree programs to better understand the details of what may be generating the excess credits within these programs. The paper finds that excess credits accounted for about 12 percent of all college-level credits earned by students who completed a degree, with substantial variation among students in different programs. Among the excess credits of students enrolled in particular programs, most were spread out over a wide variety of subject-specific and general courses. Finally, while this paper does not seek to make any normative judgments on the value of excess credits, I discuss possible reasons that may contribute to excess credits and conclude with methodologies that individual colleges and college systems could employ to assess the extent and nature of excess credits for their students, thereby allowing practitioners to ascertain the relative value of excess credits in their systems.
\end{abstract}




\section{Table of Contents}

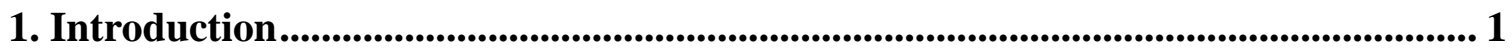

2. Data and Methodology ............................................................................................................ 2

3. The Extent of Excess Credits ....................................................................................... 5

4. Case Study: AS in Business Administration............................................................... 10

4.1 Looking at Some Transcripts in Detail ........................................................ 13

4.2 Looking at the Requirements in Detail ...................................................... 15

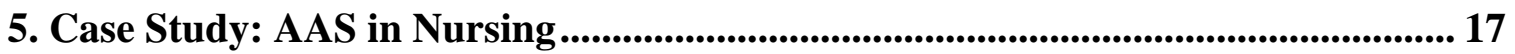

5.1 Looking at the Requirements in Detail ........................................................... 19

6. Case Study: AA\&S in General Studies ........................................................................ 20

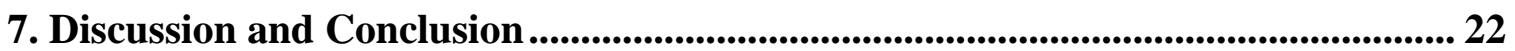

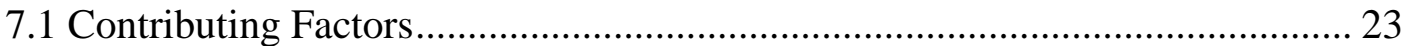

7.2 Implications and Future Steps …………………….................................. 25

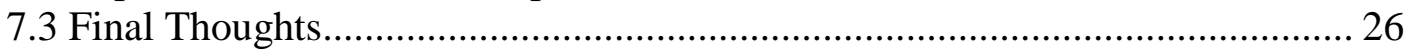

References................................................................................................................................................ 27 



\section{Introduction}

Substantial numbers of students who earn an associate degree from a community college accumulate more college credits than are required. This is an important phenomenon for at least two related reasons. First, it raises the issue of efficiency: Are students getting their degrees in the most expeditious manner, both in terms of time out of the labor market and in terms of the monetary cost of attaining the degree? Second, to what extent is the extra work undertaken by students beneficial to them, even when it does not contribute to degree attainment? The goal of this paper is to examine the extent and nature of the phenomenon of excess credits.

This paper is not the first to draw attention to the phenomenon of excess credits, and many who work in or study higher education have been familiar with the issue for some time. Complete College America (2011) recently drew attention to the matter in their report Time is the Enemy, which found that students receiving certificates earned on average 63.5 credits, even though just 30 credits are required to attain a certificate. For associate degree completers, these figures were 79 credits and 60 credits, and for bachelor's degree completers, 136.5 credits and 120 credits. A McKinsey report on raising productivity in higher education found that 14 percent of credits that were earned by students receiving a degree were in excess of degree requirements (Auguste, Cota, Jayaram, \& Laboissière, 2010).

The main contribution of this paper to the existing literature is that it considers excess credits in the context of particular degree programs in order to answer the following three questions. First, which excess credits seem to be related to the program of study that a student is pursuing, and which do not? In other words, which courses are most responsible for excess credits in each program, and are these courses related to the degrees that the students are ultimately pursing? It is true that program-related excess credits may add additional depth to a student's program, while non-program-related excess credits may add additional breadth; in any case, for a full accounting, it is necessary to assess how many excess credits fall into either category. In order to answer this question, I focus on excess credits with respect to particular programs and their requirements, and not on excess credits in general. 
Second, given the requirements of a particular program, how many excess credits are taken by students in the program relative to their overall credit requirements? In order to answer this question, I consider each specific requirement of a program and observe how many students who complete the program are exceeding that requirement and by how much.

Third, given the program mix, what is the overall quantity and estimated cost of excess credits? This approach applies a more sophisticated methodology than past studies that assumed that all associate degree programs require the same number of credits (these studies usually assumed that associate degree programs all require 60 credits; as will be demonstrated, many actually require more).

The paper is organized as follows: first, I examine the extent of excess credits overall in one community college system. Then I present case studies of individual degree programs to better understand the details of what may be generating the excess credits within these programs. The paper does not seek to make normative judgments on the value of these excess credits, but rather intends to engage in an empirical evaluation of their extent and of their distribution between program-related credits and nonprogram-related credits. However, in the conclusion of the paper, I suggest some methodologies that individual colleges and college systems could employ to assess the extent and nature of excess credits for their students, which would allow them to make their own judgments about which excess credits are relatively valuable and which are relatively less so.

\section{Data and Methodology}

This paper documents the phenomenon of excess credits by examining the credit distributions of students who earned credentials in one state's community college system (anonymized here as the State Community College System, or SCCS). This state has community college programs, many of which exist at several or many campuses with very similar requirements, as well as a statewide common course numbering system. This paper focuses on associate degree programs, which usually require about 60 to 70 credits, depending on the specific program. The paper does not include certificate programs 
because certificate programs have varying credit requirements; moreover, certificate programs are often stackable, meaning that students who complete a lower level certificate are able to enroll in a longer certificate or degree program. Thus, certificate completers pursuing longer programs would be expected to earn additional credits beyond those required for their initial certificate. (It is true, however, that the number of students who do so is often a small proportion of certificate-seeking students, depending on the particular certificate.)

I use data from six cohorts of first-time students enrolled at SCCS, from students who entered in the 2004-05 academic year to those entering in the 2009-10 year. All cohorts are tracked through fall 2010. Among the cohorts under study, students completed associate degrees in 95 distinct fields during the tracking period. This analysis is limited to the records of those students who completed associate degrees; most of these students came from the first four cohorts. The analysis undertaken here is specific to this state; while I do not know if it is representative of community college systems in other states or not, the methods outlined in this paper can be applied to other state systems.

SCCS offers five types of associate degrees. Three are transfer degrees: the Associate of Arts (AA), the Associate of Sciences (AS), and the Associate of Arts and Sciences (AA\&S). Two are terminal (non-transfer): the Associate of Applied Sciences (AAS) and the Associate of Applied Arts (AAA). Of the 14,259 completions by students in the cohorts, 72 percent were for transfer associate degrees and 28 percent were for non-transfer associate degrees. This is despite the fact that only 19 of the 95 programs are transfer programs. However, these 19 programs include the liberal arts transfer programs in which most of the system's enrollment is concentrated, and where most of the completions are as well.

Table 1 shows the 25 associate degree programs (of the total 95) with the highest numbers of graduates and the estimated credits required for each. To estimate the number of credits required for each program, I consulted the websites of two colleges that offer that program. Generally, the requirements for the same program were very similar across colleges. Where a college or pair of colleges had a range of credits required, I report that range. The 12,652 completions in these 25 programs accounted for 89 percent of all the 
Table 1

Required Credits by Program, Top 25 Programs

\begin{tabular}{|c|c|c|c|}
\hline Degree & Field & $\begin{array}{c}\# \\
\text { Completers }\end{array}$ & $\begin{array}{c}\text { Required } \\
\text { Credits }\end{array}$ \\
\hline AS & Business Admin & 1562 & 62 \\
\hline AA\&S & General Studies & 1557 & 62 \\
\hline AS & General Studies & 1487 & $60-62$ \\
\hline AS & Social Sciences & 988 & 62 \\
\hline AA\&S & Arts \& Sciences & 970 & $62-63$ \\
\hline$A A$ & Liberal Arts & 806 & $60-61$ \\
\hline AAS & Nursing & 686 & 69 \\
\hline AS & Science & 645 & $61-63$ \\
\hline AA\&S & Business Administration & 483 & $61-62$ \\
\hline AA\&S & Education & 464 & $60-62$ \\
\hline$A A \& S$ & Science & 446 & 61 \\
\hline AAS & Management & 335 & $66-68$ \\
\hline$A A \& S$ & Liberal Arts & 328 & $63-64$ \\
\hline AAS & Administration of Justice & 297 & $66-68$ \\
\hline AAS & $\begin{array}{l}\text { Administrative Support } \\
\text { Technology }\end{array}$ & 250 & $66-69$ \\
\hline AAS & $\begin{array}{l}\text { Information Systems } \\
\text { Technology }\end{array}$ & 248 & $65-68$ \\
\hline AS & Engineering & 197 & $71-72$ \\
\hline AAS & $\begin{array}{l}\text { Early Childhood } \\
\text { Development }\end{array}$ & 149 & 67 \\
\hline AAS & Police Science & 123 & $66-68$ \\
\hline AAS & Human Services & 111 & $66-67$ \\
\hline AAS & Respiratory Therapy & 106 & 72 \\
\hline AAS & Accounting & 106 & 69 \\
\hline AAS & Radiography & 105 & 72 \\
\hline AAS & Automotive & 104 & $68-69$ \\
\hline AAS & Technical Studies & 99 & $65-67$ \\
\hline
\end{tabular}

associate degree completions among students in the six cohorts. They also accounted for 88 percent of all of the credits earned by completers.

For each of these programs, I set the baseline, with respect to which excess credits are calculated, to the upper limit of the range of required credits for each program as listed on the college websites. I did this in order to be conservative in the estimates of 
excess credits, since a higher baseline implies that fewer credits are counted as excess. It appears that liberal arts programs generally have requirements of about $60-63$ credits (depending on the particular program). Nursing requires 69 credits. The AS in engineering and the various AS programs in allied health require 72 credits. Other AAS programs require 66-69 credits.

For the remaining 70 programs that I did not examine individually, I set the baseline to 62 credits for AA, AA\&S, and AS (transfer) programs, except for engineering, which I set to 72. For AAS programs, I set the baseline to 69, except for allied health programs, which I set to 72 . There may be a greater error rate here, but as noted, these account for only 12 percent of the credits earned, and I have tried to err on the side of a conservative estimate of excess credits by setting high values for the baseline.

Note also that in counting credits, I include only college-level (nondevelopmental) courses passed with a grade of $\mathrm{A}$ through $\mathrm{D}, \mathrm{P}$, or $\mathrm{S}$. While including developmental courses passed would have added about 10 percent to the credits total, such courses do not count toward a degree and therefore cannot be considered "excess" with respect to any degree.

\section{The Extent of Excess Credits}

In terms of the baselines described above, most of the 95 programs had substantial numbers of students with excess credits; the top five programs in terms of enrollment had between 50 percent and 80 percent of completers with excess credits, and, for those programs, the mean number of excess college credits (for those with those credits) was between 10 and 14. The extreme outliers had very high numbers of credits; the credits of the highest credit earner for each of these programs ranged between 128 and 155 . These outliers drive up the mean to some extent; for the top five programs, the median excess credits, for those with such credits, ranged from 7 to 10 . These figures are shown in the first five rows of Table 2. Again, none of these includes credits from developmental courses. 
Table 2

Statistics on Excess Credits for the Top 25 Associate Degree Programs in Terms of Completers, 2004-2009 Cohorts

\begin{tabular}{|c|c|c|c|c|c|c|c|c|c|c|}
\hline Degree & Field & $\begin{array}{c}\# \\
\text { Completers }\end{array}$ & $\begin{array}{c}\text { \# Completers } \\
\text { with Excess } \\
\text { Credits } \\
\end{array}$ & $\begin{array}{c}\text { Share of } \\
\text { Completers } \\
\text { with Excess } \\
\text { Credits } \\
\end{array}$ & $\begin{array}{c}\text { Median } \\
\text { Credits }\end{array}$ & $\begin{array}{c}\text { Mean } \\
\text { Credits }\end{array}$ & $\begin{array}{c}\text { Maximum } \\
\text { Credits }\end{array}$ & $\begin{array}{c}\text { Mean Excess } \\
\text { Credits (for } \\
\text { those with them) }\end{array}$ & $\begin{array}{c}\text { Median Excess } \\
\text { Credits (for } \\
\text { those with } \\
\text { them) } \\
\end{array}$ & $\begin{array}{c}\text { Excess } \\
\text { Credits } \\
\text { Index } \\
\end{array}$ \\
\hline AS & Business Admin & 1562 & 783 & $50.1 \%$ & 63 & 63.0 & 155 & 10.5 & 7 & 0.08 \\
\hline AA\&S & General Studies & 1557 & 1245 & $80.0 \%$ & 69 & 72.0 & 152 & 14.2 & 10 & 0.16 \\
\hline AS & General Studies & 1487 & 758 & $51.0 \%$ & 63 & 63.2 & 155 & 12.2 & 8 & 0.10 \\
\hline AS & Social Sciences & 988 & 729 & $73.8 \%$ & 67 & 68.6 & 155 & 11.3 & 8 & 0.12 \\
\hline AA\&S & Arts \& Sciences & 970 & 698 & $72.0 \%$ & 67 & 68.9 & 128 & 10.9 & 7 & 0.11 \\
\hline AA & Liberal Arts & 806 & 406 & $50.4 \%$ & 62 & 61.5 & 120 & 10.8 & 8 & 0.09 \\
\hline AAS & Nursing & 686 & 454 & $66.2 \%$ & 76 & 77.6 & 161 & 18.6 & 15 & 0.16 \\
\hline AS & Science & 645 & 453 & $70.2 \%$ & 69 & 70.9 & 155 & 14.3 & 11 & 0.14 \\
\hline AA\&S & Business Administration & 483 & 405 & $83.9 \%$ & 69 & 71.9 & 134 & 12.9 & 9 & 0.15 \\
\hline AA\&S & Education & 464 & 372 & $80.2 \%$ & 70 & 72.6 & 161 & 14.6 & 11 & 0.16 \\
\hline AA\&S & Science & 446 & 388 & $87.0 \%$ & 73 & 76.0 & 146 & 18.4 & 15 & 0.21 \\
\hline AAS & Management & 335 & 220 & $65.7 \%$ & 71 & 76.0 & 172 & 14.8 & 8 & 0.13 \\
\hline$A A \& S$ & Liberal Arts & 328 & 224 & $68.3 \%$ & 67 & 69.6 & 133 & 10.5 & 7 & 0.10 \\
\hline AAS & Administration of Justice & 297 & 172 & $57.9 \%$ & 70 & 72.4 & 145 & 12.8 & 8 & 0.10 \\
\hline AAS & Administrative Support Technology & 250 & 143 & $57.2 \%$ & 71 & 74.3 & 136 & 12.9 & 6 & 0.10 \\
\hline AAS & Information Systems Technology & 248 & 178 & $71.8 \%$ & 72.5 & 76.0 & 125 & 14.3 & 9 & 0.13 \\
\hline AS & Engineering & 197 & 116 & $58.9 \%$ & 75 & 75.0 & 155 & 12.7 & 9 & 0.10 \\
\hline AAS & Early Childhood Development & 149 & 73 & $49.0 \%$ & 67 & 71.1 & 121 & 14.5 & 11 & 0.10 \\
\hline AAS & Police Science & 123 & 74 & $60.2 \%$ & 71 & 73.6 & 124 & 14.1 & 12.5 & 0.12 \\
\hline AAS & Human Services & 111 & 77 & $69.4 \%$ & 74 & 79.5 & 147 & 20.5 & 13 & 0.18 \\
\hline AAS & Respiratory Therapy & 106 & 85 & $80.2 \%$ & 83.5 & 85.9 & 147 & 18.7 & 16 & 0.17 \\
\hline AAS & Accounting & 106 & 58 & $54.7 \%$ & 70 & 73.3 & 136 & 13.8 & 11 & 0.10 \\
\hline AAS & Radiography & 105 & 71 & $67.6 \%$ & 83 & 85.5 & 137 & 23.3 & 20 & 0.18 \\
\hline AAS & Automotive & 104 & 65 & $62.5 \%$ & 73 & 78.3 & 156 & 18.3 & 14 & 0.15 \\
\hline AAS & Technical Studies & 99 & 68 & $68.7 \%$ & 71 & 74.5 & 161 & 14.2 & 7 & 0.13 \\
\hline
\end{tabular}


Assessing the overall extent of excess credits involves the computation of what is referred to as the excess credit index, which is the proportion of the total degree credits earned by all completers of a program that are in excess. ${ }^{1}$ For the top five programs, this index ranges from 4 percent to 12 percent. For example, if there were 100 students in the system all pursuing the same 60-credit degree, they would need to earn 6,000 credits collectively in order to have no excess credits and an index of zero (zero/6,000). If they earned 8,000 credits collectively, or on average 80 each, the number of excess credits would be 2,000 and the index would be $0.25(2,000 / 8,000)$.

The usefulness of this index, as opposed to simply looking at the mean or median excess credits, is that it is relative; that is, it measures excess credits relative to total credits earned. Using the mean or median does not provide this type of information. This index also allows one to meaningfully compare different programs with different numbers of required credits with one another.

Looking at all 95 programs in which the number of completers ranges from 2 to 1,562 , the overall median number of program mean excess credits was 15 , the 25 th percentile was 13 , and the 75 th percentile was 19 . The median number of program median excess credits was 11 , the 25 th percentile was 9 , and the 75 th percentile was 15.5 . The median value of the index was 14 percent, the 25 th percentile was 10 percent, and the 75 th percentile was 18 percent.

Table 2 shows statistics on excess credits for the top 25 associate degree programs for completers in the cohort; as has been shown, these associate degree programs account for almost all of the credits and completions earned by completers. Here, it is clear that there were some programs with even more excess credits. For instance, the 87 percent of recipients of the AA\&S in science who had excess credits had on average 18 such credits and an excess credit index of 21 percent. For the AAS in Radiography, these numbers are 68 percent, 23 excess credits, and an index of 18. However, there are some programs with lower values. For instance, for the AS in Engineering, the figures are 59 percent of completers, 13 excess credits on average, and an index of 10 percent.

Some of the programs with the highest numbers of mean excess credits were AAS programs, such as the programs in nursing, human services, radiography, and automotive,

\footnotetext{
${ }^{1}$ I thank Clive Belfield for devising this index.
} 
in the 18 to 23 credit range. Most of the liberal arts programs had a relatively low mean excess credits level, in the 10 to 14 credit range, with the exception of the AA\&S in Science, which had 18 excess credits on average, as indicated in Table 2.

Another way to examine excess credits is to consider the credit distributions of those who completed their programs of study. Figure 1 shows the credit distributions of the completers of the top 12 associate degree programs. As you can see, each histogram has a great number of students heaped up near the program requirements, but has many students on either side. I suspect that those students with less than the required credits transferred them in from elsewhere or received credit by exam (such as Advanced Placement) or for prior experience. Those on the right side of the distribution are students with excess credits.

Figure 1

Credit Distributions, Top 12 Associate Programs

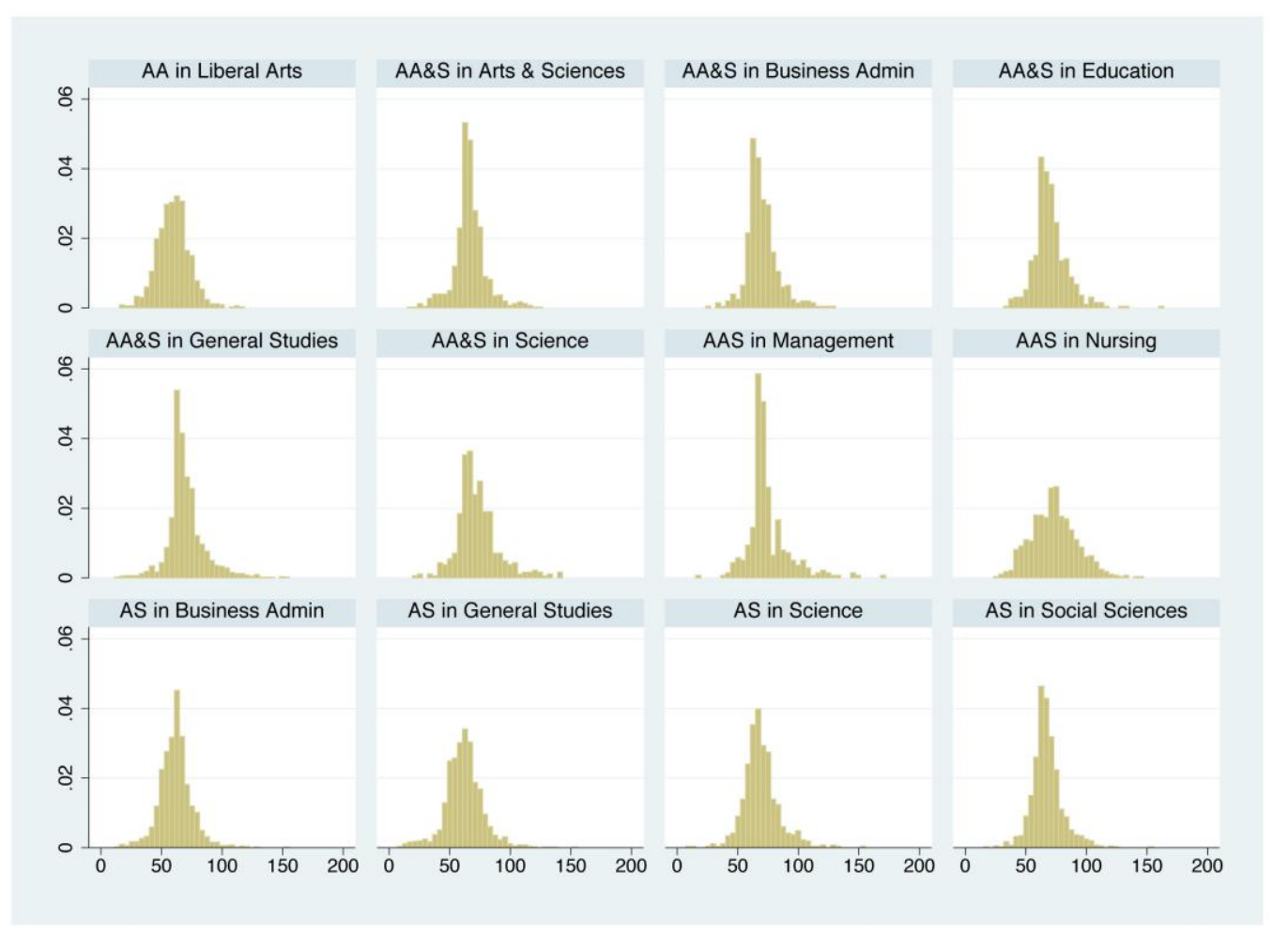

For all 14,259 associate degree completers in the period, irrespective of the program they completed, the mean number of excess credits was 14, the median was 9 , and the index was 12 percent. One student earned 175 credits, the most out of all the 
completers. Although these credits would theoretically be more than enough for a bachelor's degree, the credits are all lower-division, community college credits, so it is very unlikely that that student could have met the upper-division requirements for any bachelor's degree. These degree completers in the six cohorts earned a total of 1,002,859 credits, of which 129,093 were excess credits. (Note that the index is the ratio of these two numbers.) At an estimated cost of $\$ 277$ per credit, ${ }^{2}$ this represents a total cost of about \$36 million for the six cohorts' excess credits, or about \$6 million per year. Completers in the cohorts attempted a total of 1,418,131 credits (including successful completions, failures, and withdrawals), for a total cost of about $\$ 393$ million, or about $\$ 65$ million per year. Thus excess credits account for about 9 percent of this cost.

This assessment does not imply a normative judgment about whether the money used for excess credits was well spent. For instance, one could argue that even though these excess credits did not contribute to a credential, the students who took them learned something that enriched their minds or that they could put to use in their future careers or in other coursework. ${ }^{3}$

There is substantial variation among the colleges in the system in terms of the extent of excess credits. For instance, the mean number of excess credits varies between colleges from a low of 10.7 to a high of 21.3 , with a mean of 14.5 and a standard deviation of 2.8. For the median, the respective numbers are $7,18,10.2$, and 2.7 ; for the index, they are 7.5 percent, 22.0 percent, 14.4 percent, and 3.3 percentage points. I do not know why there is such variation, but this variation appears to indicate that some colleges have institutional features that keep such credits to a minimum that other colleges do not have. Some of the variation could be due to variation among colleges in their mix of programs, with some colleges having more enrollment in programs that generate excess credits than other colleges. There are three possible effects here. First of all, a college might have more (or fewer) students in a program that tends to generate excess credits system-wide. Second, a college might have a program that tends to generate more (or

\footnotetext{
${ }^{2}$ This is based on data from the Delta Cost Project for 2009 for the community colleges in the state in question.

${ }^{3}$ This same argument could be applied to credits that were earned by students who never earned a credential. Non-completers incur substantial costs (Schneider \& Yin, 2011). These credits, like excess credits, represent waste when thinking of an "ideal" system in which every student graduates and does so with exactly as many credits as needed and no more.
} 
fewer) excess credits than is the average for that program system-wide. Third, a college overall, due to general college-wide policies or procedures, might generate more or fewer excess credits overall, in all programs.

In this state, as in other states in which CCRC researchers have experience, most of the graduates of community colleges are in liberal arts, business, and allied health and nursing programs. For instance, in 2008-09, there were 787,325 associate degrees awarded nationwide. Of these, 263,853, or 34 percent, were in liberal arts; 111,521, or 14 percent, were in business; and 166,163, or 21 percent, were in allied health and nursing, for a total of 541,537, or 69 percent of associate degrees awarded (Snyder \& Dillow, , 2011). Among the associate degree graduates in the dataset of the current study, liberal arts, business, and nursing account for 73 percent of the 14,259 total graduates. Liberal arts graduates were 51 percent, business graduates 18 percent, and nursing graduates 5 percent. Thus, for the following case studies, I have selected one program from each of these areas. While there are multiple liberal arts and business programs, there is only one associate-level nursing program, the AAS in Nursing. For the case studies that follow, I start with business administration and nursing, since they are more focused programs of study than a general liberal arts program is, and then examine a general liberal arts program.

\section{Case Study: AS in Business Administration}

To determine more specifically what types of courses contribute to excess credits, I compare the courses taken by students with excess credits with those taken by students who just met the requirements, or who met them with just one extra course (up to four additional credits). For instance, when assessing the AS in Business Administration programs offered statewide, combined, I compare the courses taken by students with 67 or more credits, or the high-credit students, with those of the students with 62 to 66 credits, inclusive, or the medium-credit students. ${ }^{4}$ These were 21 and 28 percent of the

\footnotetext{
${ }^{4}$ I use a band of credits from the baseline requirement of credits to the baseline plus 4 , which is five credits wide, in order to capture students who just met the requirements or who went over slightly, in order to create a large enough group; if I had just selected those who had exactly the number of credits as required and no more, the group would have been too small.
} 
students, respectively. As mentioned, the state under study has common course numbering across colleges, most programs are offered at multiple colleges, and the same program at each college typically uses the same courses, with minor variations.

Because the high-credit students took more courses, they were also more likely to have taken any particular course, on average. On average is the operative phrase here, however; the high-credit group took some courses less frequently. Table 3 shows the top 10 courses that were more frequently taken by the high-credit group, restricted to courses that had an overall enrollment of at least 20 by each group.

Table 3

The Top 10 Courses in Terms of Difference in Enrollment Rate

\begin{tabular}{lccc}
\hline Course & $\begin{array}{c}\text { Enrollment Rate of } \\
\text { Medium-credit } \\
\text { Completers }\end{array}$ & $\begin{array}{c}\text { Enrollment Rate of } \\
\text { High-credit } \\
\text { Completers }\end{array}$ & Difference \\
\hline Precalculus I & 0.84 & 0.95 & 0.11 \\
Introduction to Psychology I & 0.43 & 0.51 & 0.08 \\
Principles of Public Speaking & 0.49 & 0.57 & 0.08 \\
Statistics & 0.05 & 0.12 & 0.08 \\
Beginning Spanish I & 0.10 & 0.17 & 0.07 \\
Principles of Management & 0.05 & 0.12 & 0.07 \\
Personal Stress and Stress & & 0.10 & 0.06 \\
Management & 0.04 & 0.09 & 0.06 \\
Calculus with Analytic Geometry I & 0.02 & 0.23 & 0.06 \\
College Success Skills & 0.17 & 0.12 & 0.06 \\
Precalculus II & 0.06 &
\end{tabular}

Note. Medium- and high-credit students completing the AS in business administration (minimum enrollment of 20 in each group).

It is clear from Table 3 that most of these courses are general liberal arts courses that are not specific to business, except for Principles of Management and perhaps the math and statistics courses. Therefore, some of the excess credits are probably due to these students simply taking more liberal arts courses than are required. The differences in frequency of enrollment are only moderate (6 to 11 percent), so the effect of excess credits is spread out over many courses. Note that this degree has distributional requirements, and that the public speaking courses and college success courses are required for some versions of the program. All of the remaining courses in the table 
above can satisfy either a core or distributional requirement, so this is just a situation where the high-credit students are taking more of them. It is possible that high-credit students are less likely to meet some of their requirements by transferring courses from another institution.

Program completers in the six cohorts took 316 distinct courses; of these, 210 courses, or 66 percent, were taken more frequently by the high-credit students. However, the average absolute difference in the enrollment frequency for these 210 courses was 0.016. This is the absolute difference between the enrollment frequency of the high-credit students and that of the medium-credit students. The 10 courses in Table 3 are included in these 210 , since for all of those 10 courses, the high-credit students took the course at a higher rate.

For the 106 remaining courses, which were taken more frequently by the mediumcredit students, the corresponding statistic was 0.008 . Thus the high-credit group not only had more courses that were taken more frequently, but the magnitude of the difference in frequency was higher on average than for those courses taken more frequently by the medium-credit group. The differences are small, but they add up.

Another way to compare the two groups is to consider the top enrollment courses. Table 4 shows the top 10 courses sorted by declining enrollment rate for the high-credit students. For the top six courses, enrollment is very high in both groups, presumably because they are required. Unlike in Table 3, the differences in frequency of enrollment are generally very small. Most of these courses are either business or business-related courses or other required courses such as College Composition I and II. Thus differences here are not likely to contribute much to excess credits, except for the 11 percent difference for Precalculus I, which also appeared as the top item in Table 3. It therefore appears that most of the excess credits are not to be found in these high enrollment rate courses; rather, they are spread out over a larger number of lower enrollment rate courses, many of which are not directly related to the students' major in Business Administration. 
Table 4

The Top 10 Courses by Enrollment Rate of High-Credit Students

\begin{tabular}{lccc}
\hline Course & $\begin{array}{c}\text { Enrollment Rate of } \\
\text { Medium-credit } \\
\text { Completers }\end{array}$ & $\begin{array}{c}\text { Enrollment Rate } \\
\text { of High-credit } \\
\text { Completers }\end{array}$ & Difference \\
\hline College Composition II & 0.95 & 1.00 & 0.05 \\
Principles of Accounting I & 1.00 & 1.00 & 0.00 \\
Principles of Microeconomics & 0.98 & 1.00 & 0.02 \\
Principles of Macroeconomics & 1.00 & 1.00 & 0.00 \\
Principles of Accounting II & 1.00 & 1.00 & 0.00 \\
College Composition I & 0.96 & 0.96 & 0.00 \\
Precalculus I & 0.84 & 0.95 & 0.11 \\
Introduction to Computer & 0.89 & 0.89 & -0.01 \\
Applications and Concepts & 0.80 & 0.77 & -0.03 \\
Introduction to Business & 0.68 & 0.71 & 0.03 \\
United States History I & & & \\
\hline
\end{tabular}

Note. Medium- and high-credit students completing an AS in Business Administration.

\subsection{Looking at Some Transcripts in Detail}

As another way of investigating the source of excess credits, I examine the transcripts of five students who completed the AS in Business Administration program and who were randomly selected from the group of students that had 75 credits or more. Out of a total 1,562 graduates of the program, 201 students had this many credits. It happens that the five randomly selected students were at only two colleges in SCCS, with two students at one college and three at the other. The sample here is small and unrepresentative, and therefore these findings are not generalizable, but I think they offer some insight.

The requirements for the degree at each of the two colleges are shown in Table 5. Note that the requirements are similar but not identical. The table is organized so as to highlight the similarities and differences. Both colleges require 62 credits for the degree; the first college requires 22 courses, the second, 20 .

The first two students were at the first college. The first student passed 26 courses and earned 75 credits. Over and above the basic requirements, the extra courses were two personal wellness courses, a science course, and a public speaking course. So, in this case, there was not much additional focus on business. 
Table 5

Requirements for the AS in Business Administration at Two Community Colleges

\begin{tabular}{|c|c|c|}
\hline & College 1 & College 2 \\
\hline Accounting (two semesters) & $\mathrm{x}$ & $\mathrm{x}$ \\
\hline Microeconomics & $x$ & $x$ \\
\hline Macroeconomics & $\mathrm{x}$ & $\mathrm{x}$ \\
\hline Introductory Business & $x$ & \\
\hline Introductory International Business & & $\mathrm{x}$ \\
\hline Introductory computer course & $x$ & \\
\hline Excel or Access & $x$ & \\
\hline Two math courses & $x$ & $x$ \\
\hline Probability and Statistics & & $x$ \\
\hline U.S. History or History of Western Civilization (two semesters) & $\mathrm{x}$ & \\
\hline History course & & $\mathrm{x}$ \\
\hline College Success & $x$ & $x$ \\
\hline English Composition (two semesters) & $x$ & $x$ \\
\hline Two English literature courses & $x$ & \\
\hline Two humanities courses & & $x$ \\
\hline Two laboratory science courses & $x$ & $x$ \\
\hline Two personal wellness courses & $x$ & \\
\hline Health or physical education course & & $\mathrm{x}$ \\
\hline Two additional general education courses & $x$ & $x$ \\
\hline Public speaking & & $x$ \\
\hline Total Courses: & 22 & 20 \\
\hline Total Credits: & 62 & 62 \\
\hline
\end{tabular}

The second student passed 30 courses and earned 87 credits. The extra courses were five marketing, advertising, and sales courses, a veterinary course, one statistics course, and a public speaking course. Here, there was some additional focus on business.

The remaining three students were at the second college. Although this college does not require a computer course for an AS in Business Administration, the website that describes the program indicates that computer proficiency is needed to complete the 
program, which can be achieved by taking a computer course. All three of these students took such a course, so it probably should not be considered an extra even though it does not formally count toward the program. This is an example of a phenomenon that may explain some of the excess credits in general; if programs require competencies that can be acquired through courses that do not count toward the programs' degree requirements but that can be attained through taking college-level courses, this might contribute to students' earning excess credits.

The third student (the first of the three at the second college) passed 29 courses and earned 90 credits. The extra courses were an additional economics course, a marketing course, a statistics course, a calculus course, three extra general education electives (the student took psychology, sociology, and two terms of Spanish in total), and a computer course.

So at least some of this is relevant to the major. This student received three Ds, and so perhaps took more courses in order to raise his or her GPA in order to graduate.

The fourth student passed 26 courses for 78 credits. The extra courses were an additional humanities course, a management course, an additional statistics course, an additional history course, and a computer course. Thus a fair share of the additional coursework was directly related to the student's major.

The fifth student passed 26 courses for 79 credits. This student had the following excess courses: two humanities courses, a health course, a personal finance course, and a computer course. Thus it seems that, for this student, the additional emphasis on the major was not that substantial.

Thus, this paper's examination of these five students reveals a mixed story. There seems to be some use of excess courses for additional study related to the major, but there are also quite a few courses unrelated to the major.

\subsection{Looking at the Requirements in Detail}

The final way that this paper examines excess credits is to look at the specific requirements of the AS in Business Administration at one college and then assess the extent to which students were simply meeting, or rather exceeding, each of these requirements. 
The program requires one business course, two accounting courses, two economics courses, two science courses, three humanities courses (including one history course), one computer course, one college success course, two English courses, two math courses, two physical education or recreational courses, one public speaking course, and two general electives, for a total of 21 courses.

Thirty-four percent of the students had more than one business course. Almost no students (less than 2 percent) had more than two accounting courses. Only about 1 percent of the students had more than the required two economics courses. However, 50 percent of students had more than the required two science courses.

Twenty-five percent of the students had more than the required three humanities courses. Five percent of the students had more than the required one computer course. No student took more than one college success course. Twenty-nine percent of students had more than the required two English courses (I do not count extra English as extra humanities for these purposes).

Thirty-nine percent of students had more than the required two math courses. Only about 2 percent of students had more than the two required physical education or recreational courses. No student had more than the required public speaking course.

Thus, most of the excess courses were business courses, humanities courses, English courses, math courses, and especially science courses. Except for the extra business courses, it is hard to see how these are directly related to the AS in Business Administration. It is interesting that students did not primarily concentrate their extra course-taking on subjects directly related to the program, such as economics or accounting. Of course, one can always make the case that all of the other courses might be useful in a business career.

Overall, 15 percent of students had more than the 21 courses required. For these students, the median number of courses taken was 23 , the mean was 23.9 , and the maximum was 38 .

The above analysis is an example of how colleges and college systems can audit the course-taking of their students in order to determine where the excess activity is. Once this activity is understood, colleges are better positioned to take whatever action they deem necessary, such as increasing student advising. 


\section{Case Study: AAS in Nursing}

The AAS in Nursing requires 69 credits. I compare the aggregate transcripts of medium-credit students, defined as students with 69 to 73 credits, to those of high-credit students, defined as students with 74 or more. These comprised 13 and 46 percent of the graduates, respectively. This program has an excess credits index of 16 percent, higher than average.

Table 6 shows the top 10 courses in terms of the difference in the enrollment rate of the two groups. These are courses closely related to nursing, such as Medical Terminology I and General Biology I, required distribution courses, such as College Composition II, and liberal arts electives, such as United States History I. The weight falls, however, on the required, subject-specific courses of the program itself. The differences in enrollment rates are moderate, ranging from 10 to 26 percent. It appears that a higher enrollment rate in subject-specific courses accounts for at least some of the excess credits.

Table 6 Top 10 Courses in Terms of Difference in Enrollment Rate

\begin{tabular}{lccc}
\hline Course & $\begin{array}{c}\text { Enrollment Rate of } \\
\text { Medium-credit } \\
\text { Completers }\end{array}$ & $\begin{array}{c}\text { Enrollment Rate of } \\
\text { High-credit Completers }\end{array}$ & Difference \\
\hline College Composition II & 0.54 & 0.80 & 0.26 \\
General Biology I & 0.09 & 0.33 & 0.24 \\
College Success Skills & 0.12 & 0.31 & 0.19 \\
Principles of Nutrition and Human & 0.09 & 0.27 & 0.18 \\
Development & 0.02 & 0.13 & 0.11 \\
General Biology II & 0.08 & 0.19 & 0.11 \\
United States History I & 0.14 & 0.25 & 0.11 \\
Acute Medical-Surgical Nursing & 0.29 & 0.40 & 0.11 \\
Medical Terminology I & 0.06 & 0.16 & 0.10 \\
United States History II & 0.01 & 0.11 & 0.10 \\
History and Appreciation of Art I & & & \\
\hline
\end{tabular}

Note. Medium- and high-credit students completing the AAS in nursing (minimum enrollment of 20 in each group).

These nursing programs require, as a prerequisite, high school-level algebra, chemistry, and biology; these subjects are offered at the community college, but do not count for college credit. The program does not require it, but in the case of biology, one 
can also meet this prerequisite by taking college-level biology. High-credit students appear to have been doing so at a higher rate than medium-credit students.

Table 7 shows the top 10 courses in terms of enrollment rate of the high-credit students. Here, except for College Composition II, the differences in rates between the two groups are modest. In fact, in three out of the 10, the high-credit students had a lower enrollment rate than the other students.

Table 7

The Top 10 Courses by Enrollment Rate of Medium- and High-Credit Students in the AAS in Nursing Program

\begin{tabular}{lccc}
\hline Course & $\begin{array}{c}\text { Enrollment Rate of } \\
\text { Medium-credit } \\
\text { Completers }\end{array}$ & $\begin{array}{c}\text { Enrollment Rate of High- } \\
\text { credit Completers }\end{array}$ & Difference \\
\hline College Composition I & 0.78 & 0.82 & 0.04 \\
College Composition II & 0.54 & 0.80 & 0.26 \\
Dimensions of Professional Nursing & 0.83 & 0.75 & -0.08 \\
Human Anatomy and Physiology II & 0.71 & 0.67 & -0.04 \\
Human Anatomy and Physiology I & 0.69 & 0.66 & -0.03 \\
Health Assessment & 0.64 & 0.63 & -0.01 \\
Developmental Psychology & 0.57 & 0.61 & 0.04 \\
Introduction to Computer Applications & & & 0.03 \\
and Concepts & 0.53 & 0.56 & 0.02 \\
Nursing I & 0.49 & 0.51 & 0.00 \\
Drug Dosage Calculations & 0.46 & 0.46 & \\
\hline
\end{tabular}

I conclude from this that the excess credits are probably due to two factors. The first factor is relatively high differences in enrollments in a few courses, as shown in Table 6. The second factor is small differences in enrollments over large numbers of courses. There are 207 distinct courses that were taken by both the medium- and highcredit groups; of these, 105, or 51 percent, were taken more frequently by the high-credit group. For the 105 courses, the mean absolute difference in the chances of taking one of these courses was 0.042 ; for the remaining 102, it was less, 0.023 . This means that although both groups had roughly the same number of courses for which they had a higher enrollment, the high-credit group's courses had a mean average difference in enrollment that was almost twice as high as that of the medium-credit group's, which is why they had more credits overall. Given that the differences are spread out over so many courses, it is very likely that many of the differences are not program-related, because the typical program draws on only a small subset of the courses offered by any college. 
This is the same type of pattern that appeared for the AS in Business Administration; again, many small differences in enrollment frequencies account for the difference in enrollments. Of course, this is not surprising because the high-credit group took more courses on average, by definition. It may be the case, as CCRC researchers have heard informally from some colleges, that many nursing students take liberal arts courses while they are waiting for formal admission to the nursing program, since many nursing programs have more applicants than they can enroll.

\subsection{Looking at the Requirements in Detail}

As was the case with the AS in Business Administration, this paper considers the specific requirements for the AAS in Nursing at one college, and looks at the extent to which students are exceeding them.

This degree requires nine nursing courses, two biology courses, two health courses, one math course, one English course, one psychology course, one college success course, one sociology course, one computer course, and one humanities course, for a total of 20 courses.

Nineteen percent of the students had more than the required nine nursing courses. Sixteen percent had more than the required two biology courses. Nineteen percent had more than the required two health courses.

Only 5 percent of students, on the other hand, had more than the required one math course. Twenty-six percent of students had more than the required one English course. Twenty-three percent of students had more than the required one psychology

course. No student took more than the one required college success course. Eight percent of students took more than the one required sociology course. Six percent of students took more than the one required computer course, and 31 percent of students took more than the one required humanities course.

Overall, 45 percent of students took more than the required 20 courses. For these students, the median number of courses taken was 24 , and the mean was 25.2 . The most courses taken was 34 .

The main foci of extra course-taking were on nursing, biology, health, English, psychology, and the humanities. So, more than was the case for the business students at 
the college examined in a similar manner above, the excess course-taking was on subjectrelated material. However, the highest percentages of students taking extra courses were in subjects not directly related to the field: humanities, psychology, and English, although, again, one can make the case that these courses are broadly useful.

\section{Case Study: AA\&S in General Studies}

The third and final case study is of the Associate of Arts and Sciences in General Studies. This was the second most frequently completed degree in the period, with 1,557 completers, barely fewer than the 1,562 that completed the AS in Business

Administration. Unlike the previous two case studies, the degree in question is a general liberal arts lower division degree, with no particular focus on any subject. I include it as a case study because general liberal arts students are the largest group in this system (at 51 percent of graduates) and because they are the largest group in community college systems in general. This degree requires 62 credits; I define medium-credit students as students with 62 to 66 credits. I define high-credit students as students with 67 or more credits.

Table 8 shows the top 10 courses in terms of the difference in enrollment rate, conditioned on a minimum enrollment in each course of 20 or more.

Table 8

Top 10 Courses in Terms of Difference in Enrollment Rate

\begin{tabular}{lccc}
\hline Course & $\begin{array}{c}\text { Enrollment Rate of Medium- } \\
\text { credit Completers }\end{array}$ & $\begin{array}{c}\text { Enrollment Rate of High- } \\
\text { credit Completers }\end{array}$ & Difference \\
\hline Principles of Macroeconomics & 0.20 & 0.32 & 0.12 \\
Statistics I & 0.05 & 0.16 & 0.11 \\
College Chemistry I & 0.11 & 0.20 & 0.09 \\
Principles of Microeconomics & 0.12 & 0.21 & 0.09 \\
Principles of Accounting II & 0.03 & 0.12 & 0.08 \\
Human Anatomy and & & & 0.08 \\
Physiology I & 0.03 & 0.11 & 0.08 \\
Precalculus I & 0.54 & 0.62 & 0.08 \\
Principles of Accounting I & 0.10 & 0.18 & 0.07 \\
United States History I & 0.73 & 0.80 & 0.07 \\
U.S. Government I & 0.17 & 0.24 & \\
\hline
\end{tabular}

Note. Medium- and high-credit students completing the AA\&S in General Studies (minimum enrollment of 20 in each group). 
These all have moderate differences on the order of 7 to 12 percent. It appears that high-credit students were taking certain liberal arts courses, including economics, chemistry, government, and statistics, at a higher rate, as well as accounting, which is a business course. Given that four of these courses are economics and accounting, it appears that high-credit students in this field had an interest in business; perhaps some of them intended to become business majors but did not reach that goal and instead ended up with a general studies degree.

Table 9 shows the top 10 courses by enrollment rate of the high-credit students, and compares the enrollment rate to that of the medium-credit students. Generally, the enrollment rates are very similar. It appears that the high enrollment rate courses were largely the same for both groups, and included subjects such as English composition, biology, history, math, computers, psychology, and sociology. Thus, these high enrollment rate courses probably do not account for that many of the excess credits in most cases, except when the difference is relatively high (as is the case with United States History I, with a difference of 0.07).

Table 9

The Top 10 Courses by Enrollment Rate of High-Credit Students

\begin{tabular}{lccc}
\hline Course & $\begin{array}{c}\text { Enrollment Rate of } \\
\text { Medium-Credit } \\
\text { Completers }\end{array}$ & $\begin{array}{c}\text { Enrollment Rate of } \\
\text { High-Credit Completers }\end{array}$ & \begin{tabular}{c} 
Difference \\
\hline College Composition II
\end{tabular} College Composition I $_{\text {General Biology II }}$ \\
General Biology I & 0.98 & 1.00 & 0.01 \\
United States History I & 0.83 & 0.99 & 0.01 \\
United States History II & 0.83 & 0.82 & -0.01 \\
Introduction to Computer & 0.73 & 0.81 & -0.01 \\
Applications and Concepts & 0.73 & 0.80 & 0.07 \\
Principles of Psychology & 0.74 & 0.78 & 0.05 \\
Precalculus I & 0.61 & 0.75 & 0.01 \\
Principles of Sociology & 0.54 & 0.63 & 0.01 \\
\hline
\end{tabular}

Note. Medium- and high-credit students completing the AA\&S in General Studies.

There were a total of 526 distinct courses taken by both of these groups. Of these, 350 , or 62 percent, were taken more frequently by the high-credit group; the remaining 176 were taken more frequently or as frequently by the medium-credit group. But, as 
with the other two case studies, the mean absolute difference in the frequency is higher for the courses taken more frequently by the high-credit group; it is 0.013 . For the 176 courses, the corresponding number was 0.008 . The excess credits were caused mainly by two factors: a few courses with large differences in enrollment, and many courses with small differences.

In contrast to the previous two case studies, I do not conduct a detailed requirements study for this degree. However, on average, this degree requires about 22 courses. Fifty-two percent of the completers had more than this number of courses. The mean number of extra courses, for those that had them, is 4.9 , and the median is 3 . This is consistent with the corresponding numbers of 14.2 and 10 for credits.

\section{Discussion and Conclusion}

Excess credits appear to be a significant phenomenon among community college associate degree completers. In this examination of excess credits in one community college system, they account for about 12 percent of all college-level credits successfully completed by students who earned a degree. The costs are also significant; for the system used in this study, I estimated the costs at about $\$ 6$ million per year, which is about 9 percent of the total cost of credits attempted by these students. The costs would have been higher if the analysis had included courses failed or dropped among the excess credits; such courses were not included. They would also be higher if developmental credits had been included, since these credits do not count toward a degree.

I found substantial variation across programs in terms of the extent of excess credits. Excess credits were generally more prevalent in AAS programs than they were in transfer associate degree programs. However, all programs that I examined had significant proportions of their students (almost always more than half) earning excess credits and significant average levels of excess credits for those students that had them, typically in the 10 to 20 range. 


\subsection{Contributing Factors}

I carried out three case studies of excess credits in three different programsbusiness, nursing, and general studies. I found that most excess credits could not be attributed to just a few courses but instead were spread out over a wide variety of courses. I also found that both subject-specific and general courses accounted for excess credits, with neither dominating the story.

Why are students earning excess credits? There are several possible reasons. Each of the following factors probably plays a role, but the relative weight of them is hard to determine.

Students entering community colleges often do not have a good idea of what they want to do or what they want to study. As a result, they may take courses in a variety of areas to explore. When it comes to the degree program they decide upon, often not all of these early courses will count for the degree and may thus end up as excess.

Related to this is limited advising available to many community college students. If students are not given good information about what courses they need to complete a degree, they may be more prone to taking courses that they do not need. Or they may be directed to a major or program that is a poor fit for them and then need to change direction. Or they may choose a major, do poorly in it, and be forced as a result to change direction toward one in which they can do better. For instance, a student might start out in business but do poorly in economics, and so may end up with a general studies degree. Another way that academic performance can play a role is if students end up having to repeat courses if their GPA is not high enough to graduate in a particular program, or if they take additional courses to raise their overall GPA, hoping to earn higher grades in those courses.

Structural or scheduling barriers also play a role. For instance, a student may need to take course A, but that course may not be available or convenient in a given semester; it may be full or scheduled at a bad time for the student. Instead, the student takes course $\mathrm{B}$ in order to maintain full-time status and remain eligible for financial aid. Or a student may be waiting to be accepted into a program and may take other courses in the meantime. Colleges have indicated that this is common in the case of nursing programs. 
Another possible factor is that students may take courses that are not formally required for a program in order to acquire knowledge needed to succeed in that program. For instance, a program may require knowledge of computers but not formally require a computer course. Some students may end up taking such a course in order to acquire the necessary knowledge, and the course will end up being counted as excess because it raises the students' credits above the required level.

Yet another factor is the issue of transfer. If students know that they can transfer credits over and above the number required for their degree, they may acquire more credits and transfer all of them, perhaps because acquiring credits is less expensive at a community college than at their transfer destination. The reverse situation occurs when a student has enough credits to graduate, but not all of her credits transfer, so she ends up having to take additional courses.

In order to explore the transfer issue, I examined the transfer policies of the top 10 four-year colleges in this state in terms of community college transfers accepted. The first college accepts up to 90 credits. The second college accepts as many transferable credits as the student has, with no limit. The third college has no maximum as well, but at least 30 credits must be from the receiving institution. The fourth college will accept up to 63 credits. The fifth will accept up to half of the final degree requirements (60 of 120 credits).The sixth has no limit, but at least 48 credits must be taken at that college. The seventh has guaranteed admission for community college graduates, but has a complex set of requirements that does not allow the specification an overall number of transfer credits. The eighth has no limit. The ninth will allow up to 60 percent of the credits for a degree to be taken at a community college. And the 10th college will accept up to 60 credits.

Thus the potential for allowing excess credits to count toward a four-year degree varies by institution; some admit the possibility, others do not. However, the data do not allow investigation of whether the students who transferred with excess credits actually were able to take advantage of such policies. (I did not have access to student transcripts at the transfer institutions for this paper. I hope that in the future I will obtain access to data which will shed further light on this question.) 
Another factor is student interests and marginal costs. If the marginal tuition for an additional course in a given semester is zero or quite low-that is, if the college does not charge much more for five or six courses in a semester as opposed to four-a student may take an additional course or two because she is interested in it, even if it does not count toward her degree. The main cost for attending school for most students may be the opportunity cost of not working, so if they are already attending school full time and not working, then the additional cost of another course may not be meaningful to them. What is more, the course may be of use occupationally. For example, an additional computer course may be useful even though only one computer course is required. Students seeking double majors are another, similar, kind of source of excess credits. Finally, transfer students may take occupational courses to "hedge their bets"; conversely, occupational students may take liberal arts courses with the idea of someday getting a bachelor's degree.

\subsection{Implications and Future Steps}

The extent to which each of these factors contributes to excess credits is unknown. One way that colleges can proceed in determining whether particular kinds of excess credits are actually useful is to, at least once a term, conduct a degree audit of students and compare courses completed with degree requirements. I refer to this as a "continuous degree audit" (as opposed to the degree audits that are carried out only when a student applies to graduate). This can be done only for those students whose target program is known. However, the process of conducting such an audit can create an opportunity for students, faculty, advisors, and administrators to increase the number of students who have specified a program.

Such an audit could be conducted with completing students as well. The two sample audits of two particular programs that I carried out above, of the nursing program at one college and the business program at another, are an example of how such audits might be done. For students whose programs are still in progress, the audit can be used to see how well their coursework lines up with the program that they are aiming to complete. If some students appear to be off track, they can be given additional advising. 
For students who have completed their programs, the audit can then consider the courses that were most commonly completed that exceeded each requirement of the program and attempt to ascertain the value to students of these courses and why students chose them. Were they used after transferring? Did they provide useful occupational skills? Focus groups with students might help to clarify these questions. Steps can then be taken to address institutional challenges that may be generating "problem" credits, if any are identified. For instance, if it is found that students are taking extraneous courses because they cannot access the courses they need, efforts could be made to open up additional sections of those needed courses. Or if students are taking extra courses that will not transfer, additional efforts might be made to inform them as to what courses will transfer. Understanding the pattern of excess credits is the first step toward discovering what reforms are needed, and many colleges still need to carry out this first step.

\subsection{Final Thoughts}

It is clear that not all excess credits are necessarily a problem. If a student attains extra credits that do not count toward a degree but that can be transferred to another institution, or that strengthen his or her practical skills, such credits may be useful for all concerned. It is unrealistic to envision a system where every degree completer obtains only the credits required and no more. On the other hand, contributing factors to excess credits where students are truly "spinning their wheels," such as poor advising, unstructured program pathways with excessive electives, unclear transfer policies, and structural barriers, can be addressed by colleges and policymakers, who can work to reduce those excess credits that are truly not useful in helping students learn and progress in their education. 


\section{References}

Auguste, B. G., Cota, A., Jayaram, K., \& Laboissière, M. C. A. (2010). Winning by degrees: The strategies of highly productive higher education institutions. New York, NY: McKinsey \& Company.

Complete College America. (2011). Time is the enemy. Washington, DC: Author.

Schneider, M., \& Yin, L. (2011). The high cost of low graduation rates: How much does dropping out of college really cost? Washington, DC: American Institutes for Research.

Snyder, T. D., \& Dillow, S. A. (2011). Digest of education statistics 2010 (NCES 2011015). Washington, DC: U.S. Department of Education, Institute of Education Sciences, National Center for Education Statistics. Retrieved from http://nces.ed.gov/pubs2011/2011015.pdf 